\title{
The use of novel Thick-Film sensors in the estimation of soil structural changes through the correlation of soil electrical conductivity and soil water content
}

\author{
Marios Sophocleous $^{1 *}$, John K. Atkinson ${ }^{2}$, Joel Smethurst ${ }^{2}$, Gerardo Espindola ${ }^{2}$ and Alessia \\ Ingenito ${ }^{2}$ \\ ${ }^{1}$ Department of Electrical \& Computer Engineering, EMPHASIS Research Centre of the University of Cyprus, \\ Nicosia, 2109, Cyprus \\ ${ }^{2}$ Faculty of Engineering \& Physical Sciences, University of Southampton, Southampton, SO17 1BJ, UK
}

\begin{abstract}
Novel, low-cost, screen-printed (thick-film) conductivity sensors have been incorporated into laboratory-based soil columns together with water-content sensors, so that changes in the soil structure could be monitored through correlation of changes in soil conductivity and water content during cyclic wetting and drying of the soil. Significant differences were found in the relationship between the electrical conductivity and water content (CWC) characteristics for the different soil types tested. It was also found that cyclic wetting and draining of the soils, such as would occur due to natural climate effects, produces changes in the $\mathrm{CWC}$ characteristics that are indicative of soil structural change.
\end{abstract}

Keywords: Soil conductivity, water content, Thick-Film sensors

\footnotetext{
${ }^{*}$ Corresponding author.

E-mail address: sophocleous.marios@ucy.ac.cy (M. Sophocleous).
} 


\section{Introduction}

Road, rail and canal network operators own extensive geotechnical assets (earth cuttings and embankments) that need to be managed in a cost-effective and sustainable way while maintaining an appropriate service level that meets economic social, safety and environmental requirements [1]. Instability of earthworks is a major factor influencing the safety and reliability of transport networks. Water infiltration into soil from rainfall and snowmelt increases the degree of soil saturation, which in turn triggers slope failures. The effect of rain infiltration on slope stability is well established within the literature [2,3]. Significant research effort over the last twenty years has been focused on understanding the triggering mechanisms for landslides, their spatial and temporal distributions and consequences [4].

Instability in natural and engineered slopes can occur due to progressive geotechnical property changes in response to variations in soil water content and pore water pressures driven by seasonal wetting and drying [5]. Clay soils are prone to a process of strain-softening where the soil reduces in strength with increasing shear strain. This enables slopes to progressively lose strength, often over many years, as clay shrink-swell caused by seasonal variations in water content causes an accumulation of shear strain [6,7]. Cyclic wetting and drying of soils can also cause changes to their fabric: in clays, the changes are caused principally by soil cracking and fissuring during drying. This has been demonstrated to alter the water retention behaviour, and cause a reduction in the shear strength of the clay [8]. Natural silt and sand materials can also be influenced by wetting and drying. Silts and sands with a relatively loose particle packing are often formed naturally by Aeolian and slope wash processes. When partially-saturated (i.e. the void space contains both air and water) the particle packing is often supported by soil water tensions caused by formation of meniscus at the inter-particle contacts. When the soil becomes saturated, such as during a heavy rainfall event, the water tensions are reduced or lost, and the material can collapse to a denser soil particle arrangement resulting in a form of 'wetting collapse'.

Hydro-geophysical monitoring of soil water storage and fluxes has been quite widely used for understanding slope hydrology in the field [9-11]. Resistivity measurements have been used in the laboratory alongside measurements of soil water content, and notably demonstrated to change as successive wetting and drying cycles alter the structural fabric of the soil [8].

Due to the complexity of the soil materials and how they may change over time, the condition of slopes and their resilience to climatic stresses can be difficult to determine. Current approaches to their characterisation and monitoring feature several limitations $[5,12]$. Common slope monitoring techniques involve drilling boreholes and installing deep instrumentation to measure soil water pressures or displacements. This is expensive to do, and therefore monitoring of slopes is limited to only a small number that are exhibiting obvious signs of failure $[13,14]$.

The ability to predict failure in long lengths of earthwork would be of major benefit to operators of transport systems, and indeed other infrastructure stakeholders, in that not only could potential safety risks be identified and avoided, but through early intervention and remedial operations it may also be possible to prevent earthwork failure and subsequent loss of service [15]. This has led to the idea that simple and low cost sensors could be developed that might indicate progressive change in earthwork condition and thus provide enhanced information about possible instability [14]. Investigations of limited numbers of wetting and drying cycles [8] have led to the postulation that if changes in soil structure resulting from environmental cycling can be tracked and classified such that those likely to produce failure can be identified at an early stage, it would be possible to infer the likelihood of failure from the changes in soil structure measured by suitable buried sensors.

In the study reported here, novel low-cost, thick-film screen-printed conductivity sensors have been incorporated into laboratory soil columns together with water content sensors to 
investigate changes in soil conductivity and water content during cyclic saturation and draining of the soil columns.

\section{Methodology}

\subsection{Experimental Procedure \& Setup}

A test rig was manufactured in order to test soil structural characteristics using the novel lowcost, thick-film screen-printed conductivity sensors and by correlating their outputs with those of commercially available water content sensors, such as those that use electrical permittivity to measure the dielectric constant of the soil (Delta-T Devices MLX2 Theta Probe). The test rig consisted of a $1 \mathrm{~m}$ tall cylindrical column with a diameter of approximately $0.3 \mathrm{~m}$ having several holes on the sides to allow the sensors to be inserted at various depths. As shown in Fig. 1 below, the bottom $0.06 \mathrm{~m}$ section of the column was filled with gravel to facilitate faster drainage rates, with a geotextile filter used to separate the test sample from the gravel and prevent fine particle washout. The soil sample was poured dry into the column from $0.06 \mathrm{~m}$ to $0.34 \mathrm{~m}$ and the sensors were inserted in the soil sample at around $0.3 \mathrm{~m}$ from the bottom of the column (Fig. 1). The sensors were completely covered by the soil sample but placed high enough in the column to obtain faster drainage and hence the attainment of quicker experimental runs. The Theta Probe was inserted at the same height as the screen-printed conductivity sensor to ensure compatibility of readings. Using a peristaltic pump, the column was then filled slowly with de-aerated water through the drainage pipe at the base. The method of filling slowly from the base was designed to prevent air being trapped in the sand, and obtain close to $100 \%$ saturation. The column was filled with water up to $0.5 \mathrm{~m}$ to ensure it completely covered the sensors. Once the column was filled with water, the pump was removed and the column drainage rate was controlled through a valve in the drainage pipe. Readings were recorded from before the drainage valve was opened and continued until the column had drained, although the soil samples were always found to retain some water under gravity. This procedure was repeated several times for the same soil type without replacing the column soil to observe the relationship between soil properties and cycle number.

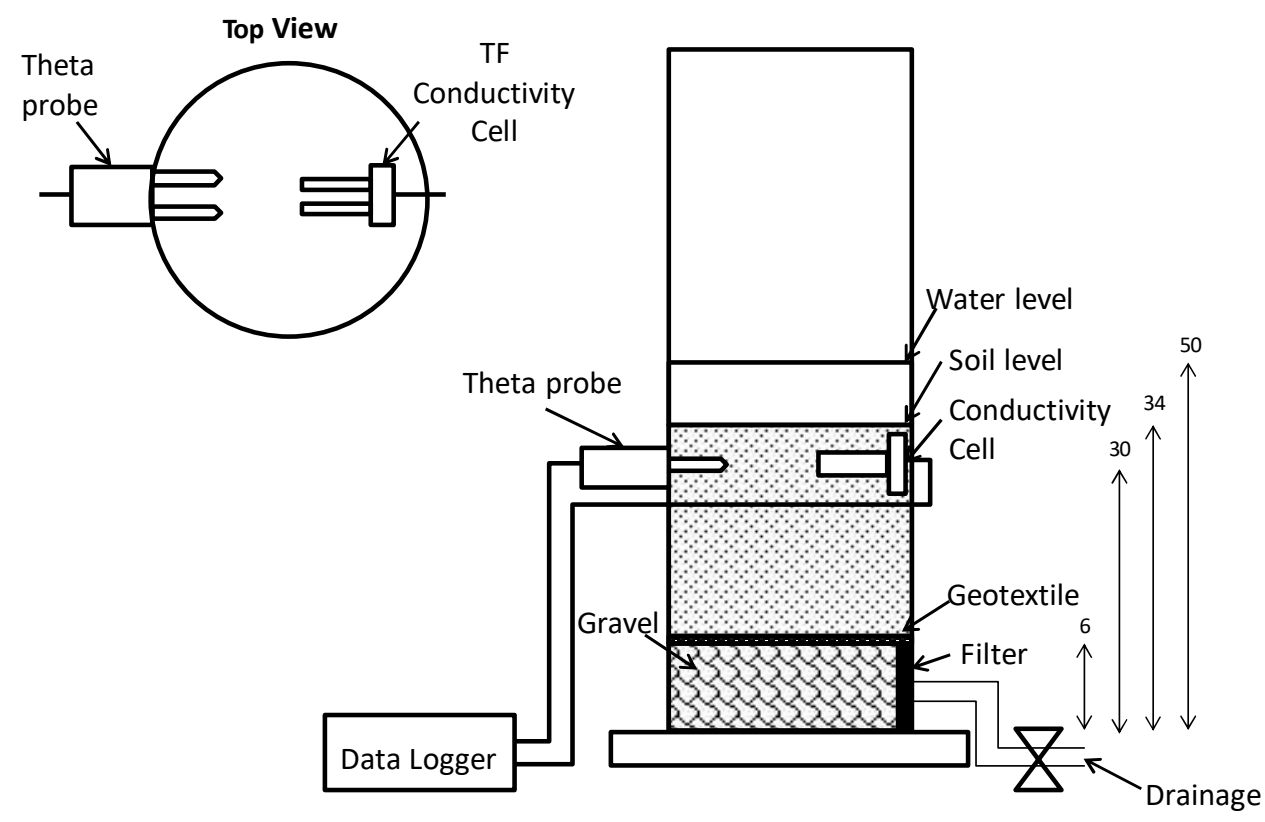

Fig. 1. Schematic of the test rig showing sensor orientation and positioning (all dimensions in $\mathrm{cm}$ ).

The Theta Probe was independently calibrated for each soil sample according to the manufacturer's instructions, with readings recorded using a Delta-T Devices GP2 data logger. The thick-film conductivity sensor was based on the 4 electrodes method, employing an 
alternating polarity square wave current source at a frequency of $1 \mathrm{kHz}$ for the drive signal to the current sourcing electrodes and measuring the resulting potential difference across the voltage sensing electrodes. Drive current levels were adjusted in order to afford different sensitivities for different conductivity ranges. Fig. 2 shows the structure and dimensions of the sensor. The volume of the soil that was being tested was $6500 \mathrm{~mm}^{3}$, which is 10 to 1 million times greater than the largest particle size in order to allow homogeneity. More details on the construction, fabrication and operation of the conductivity sensor can be found elsewhere [1619].
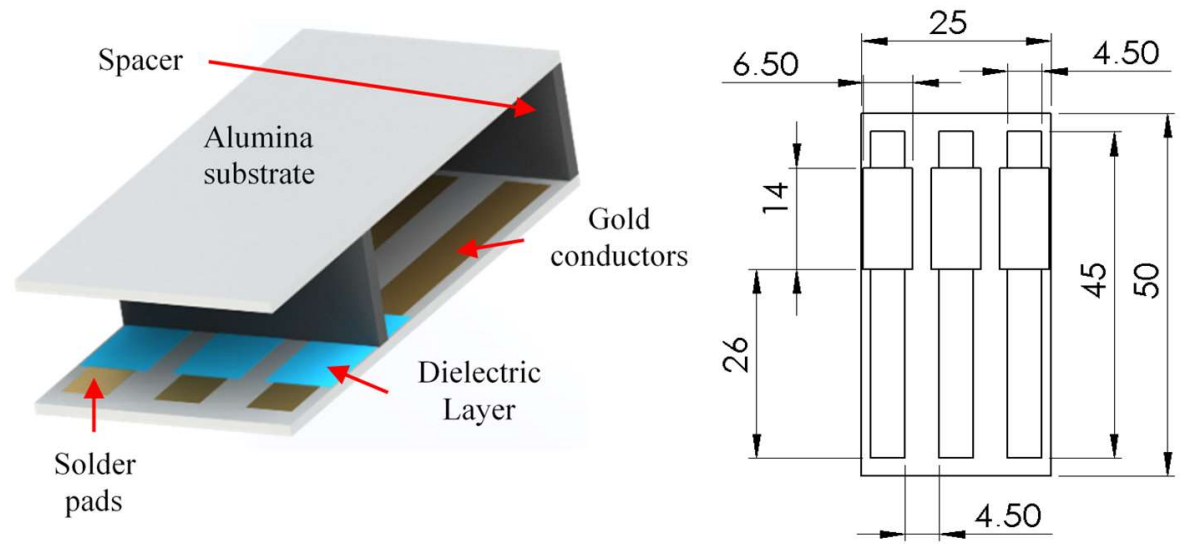

Fig. 2. (Left) Sensor parts and (right) sensor's dimensions in mm.

The instrumentation circuit employed with the conductivity sensor phase synchronously measures the alternating voltage waveform across the conductivity cell inner electrode pair. This results in the production of a DC voltage proportional to conductivity that is suitable for data logging using a Campbell Scientific CR1000 data logger. By knowing the amplitude of the driving current source employed and simply by applying Ohms Law it is possible to deduce soil resistance in the conductivity cell and hence also the soil conductance as the reciprocal of the resistance. It is also possible to obtain a value of conductivity from the conductance reading using the cell constant of the sensor. This can be deduced from an in-situ calibration of the sensor taking into account any field fringing of the drive current, although in this case the degree of fringing is not considered to be significant due to the deliberate construction of the sensor to minimise this effect over the range of conductivities encountered [17,18,20-22]. Thus conductivity could be inferred quite closely simply by dividing the measured conductance by the geometric cell constant of the thick-film sensor, which throughout the tests had a value of $0.031 \mathrm{~m}$. However due to the nature of the experiments conducted here an exact cell constant was not obtained, and the results in the following sections are reported as conductance $(\mathrm{mS})$ versus water content $\left(\mathrm{m}^{3} / \mathrm{m}^{3}\right)$. In the results reported here and their subsequent discussion, it is the change in the measured values as a function of water content for different soils that is important and as such it is not relevant whether these changes are reported as conductance or conductivity.

\subsection{Soil Sample Preparation}

Three different soil types were used, Leighton Buzzard type E sand, commercial Builder's sand and a Sand-Silt-Clay mixture. Leighton Buzzard type E sand has a narrow range of particle sizes (most between $150 \mu \mathrm{m}$ and $300 \mu \mathrm{m}$ ), thus forming a material of fairly low dry density. It was specifically chosen as it has the ability to retain some water yet allows the test to run (drain) relatively quickly. To ensure that the sand was placed at a consistent dry density of $1.79 \mathrm{Mg} / \mathrm{m}^{3}$, it was poured in to the column through a $1 \mathrm{~m}$ tall pluviation tube in 4 lifts, with the tube base maintained at a height of $70 \mathrm{~mm}$ above the sand surface. The column was then slowly filled from the bottom with de-aerated water at a rate of $0.87 \mathrm{~mL} / \mathrm{s}$ until a total water column height of $500 \mathrm{~mm}$ above the drainage point was obtained. 
Compared with the Leighton Buzzard sand, the Builder's sand is characterized by a greater average particle size and less homogeneity ( $90 \%$ of the sample between $150 \mu \mathrm{m}$ to $600 \mu \mathrm{m})$. In keeping with the previous experiments, the Builder's sand was also poured into the column using the pluviation tube in 4 lifts, again maintaining the base of the tube $70 \mathrm{~mm}$ above the surface of the sand, to give a dry density of $1.85 \mathrm{Mg} / \mathrm{m}^{3}$. The column was also slowly filled from the bottom with de-aerated water at a rate of $0.87 \mathrm{~mL} / \mathrm{s}$, until a water column of height $500 \mathrm{~mm}$ had formed.

The Sand-Silt-Clay mixture used in the experiments was characterized by a greater capacity to retain water. The mixture was formed from Leighton Buzzard sand (fractions B, C and D), silt (HPF5) and clay (Hymod Prima). Table 1 summarizes the actual soil composition used. This soil mixture is specifically designed to give a high density, with the finer silt and clay particles filling the voids of the larger sand fraction.

Table 1: Proportions of different constituent materials in Sand-Silt-Clay mixture

\begin{tabular}{|c|c|c|c|c|}
\hline \multicolumn{3}{|c|}{ SAND } & SILT & CLAY \\
\hline $\begin{array}{c}\text { Leighton } \\
\text { Buzzard } \\
\text { fraction B } \\
{[\%]}\end{array}$ & $\begin{array}{c}\text { Leighton } \\
\text { Buzzard } \\
\text { fraction C } \\
{[\%]}\end{array}$ & $\begin{array}{c}\text { Leighton } \\
\text { Buzzard fraction } \\
\text { C }[\%]\end{array}$ & $\begin{array}{c}\text { HPF5 } \\
{[\%]}\end{array}$ & Hymod Prima [\%] \\
\hline (Particle size: & (Particle size: & (Particle size: & (Particle size: & (Particle size: \\
\hline $1.18-0.6 \mathrm{~mm})$ & $0.6-0.3 \mathrm{~mm})$ & $0.3-0.15 \mathrm{~mm})$ & $0.2-0.005 \mathrm{~mm})$ & $0.005-0.0005 \mathrm{~mm})$ \\
\hline 51 & 11 & 11 & 19 & 8 \\
\hline
\end{tabular}

Due to the different nature of the soil and in order to avoid a very lengthy test time, a slightly different test rig configuration was used in that the gravel filter at the bottom of the column was increased to $280 \mathrm{~mm}$ in height, with a test soil band of $70 \mathrm{~mm}$ containing the sensors. Fig. 3 summarizes the test rig changes.

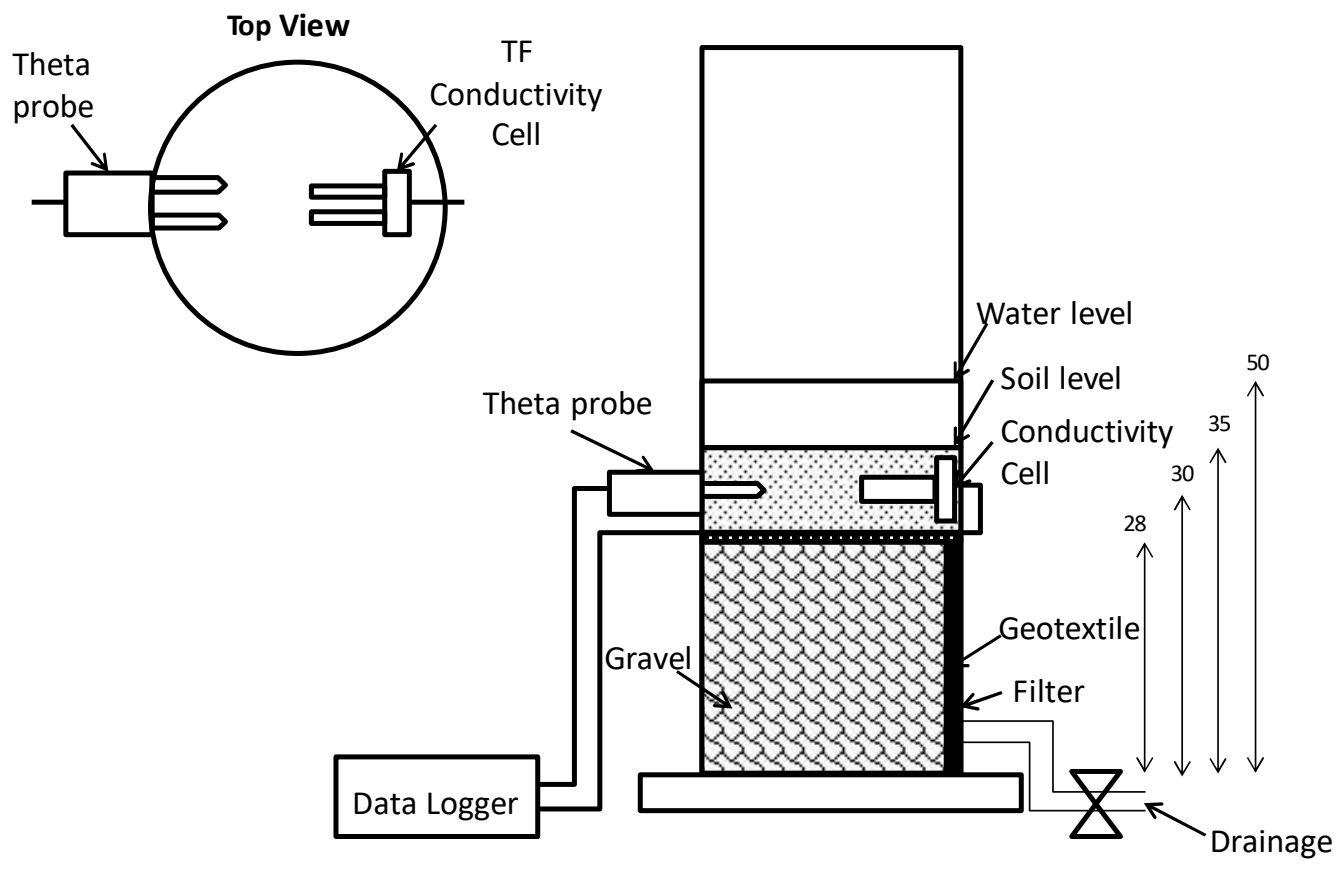

Fig. 3. Altered test rig for the Sand-Silt-Clay mixture test (all dimensions in $\mathrm{cm}$ ) 
The Sand-Silt-Clay mixture was prepared by hand mixing in plastic bags the constituents in Table 1 with an initial water content of $8 \%$. In order to ensure adequate hydration of the clay and silt and prevent evaporation of water, the mixture was left in sealed plastic bags for 24 hours. The mixture was then placed into the column in two lifts using Proctor compaction rules to control the soil density. The Proctor method suggests the use of $40 \mathrm{~mm}$ deep layers using a $2.5 \mathrm{~kg}$ metal rammer falling through $300 \mathrm{~mm}$, hence the column was placed in 2 steps, each of which was initially $40 \mathrm{~mm}$ before compaction. The average dry density based on the weight and volume of the placed soil was calculated to be $2.09 \mathrm{Mg} / \mathrm{m}^{3}$.

\section{Results}

Each of the experimental runs produced a set of results typically as shown in Fig. 4 where the electrical conductance measured by the thick-film sensor is seen to be decreasing with time as the water content reduces as the column drains.

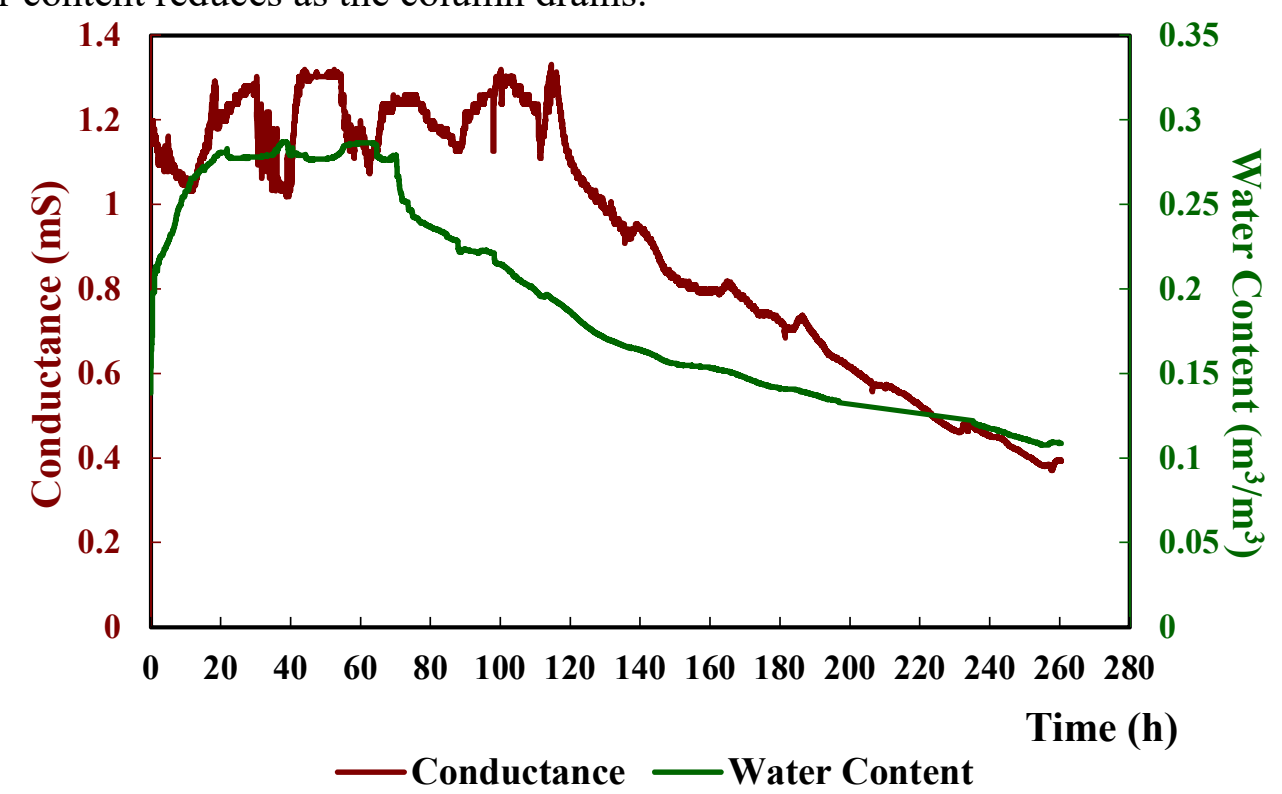

Fig. 4. Typical cycle result for electrical conductance and water content obtained in this case as a second wetting/drainage cycle of Sand-Silt-Clay with a conductivity sensor drive current level of $1 \mathrm{~mA}$ and a water drainage rate of $0.97 \mathrm{~mL} / \mathrm{s}$.

The data from each experimental run were then used to plot curves of electrical conductance versus water content for subsequent cycles of wetting and drying for each of the three tested soil types. Conductance was simply plotted as the reciprocal of the measured resistance which in turn was derived from the logged output voltage divided by the sensor drive current amplitude.

Fig. 5 shows plots of conductance versus water content for the Leighton Buzzard sand over four cycles of wetting and draining of the soil column. The results are presented as conductance $(\mathrm{mS})$ versus water content $\left(\mathrm{m}^{3} / \mathrm{m}^{3}\right)$ over the duration of each of the drainage cycles. Inspection of Fig. 4 shows that both the values of absolute conductance versus water content, and importantly their slopes, reduce with successive wetting and draining cycles. 


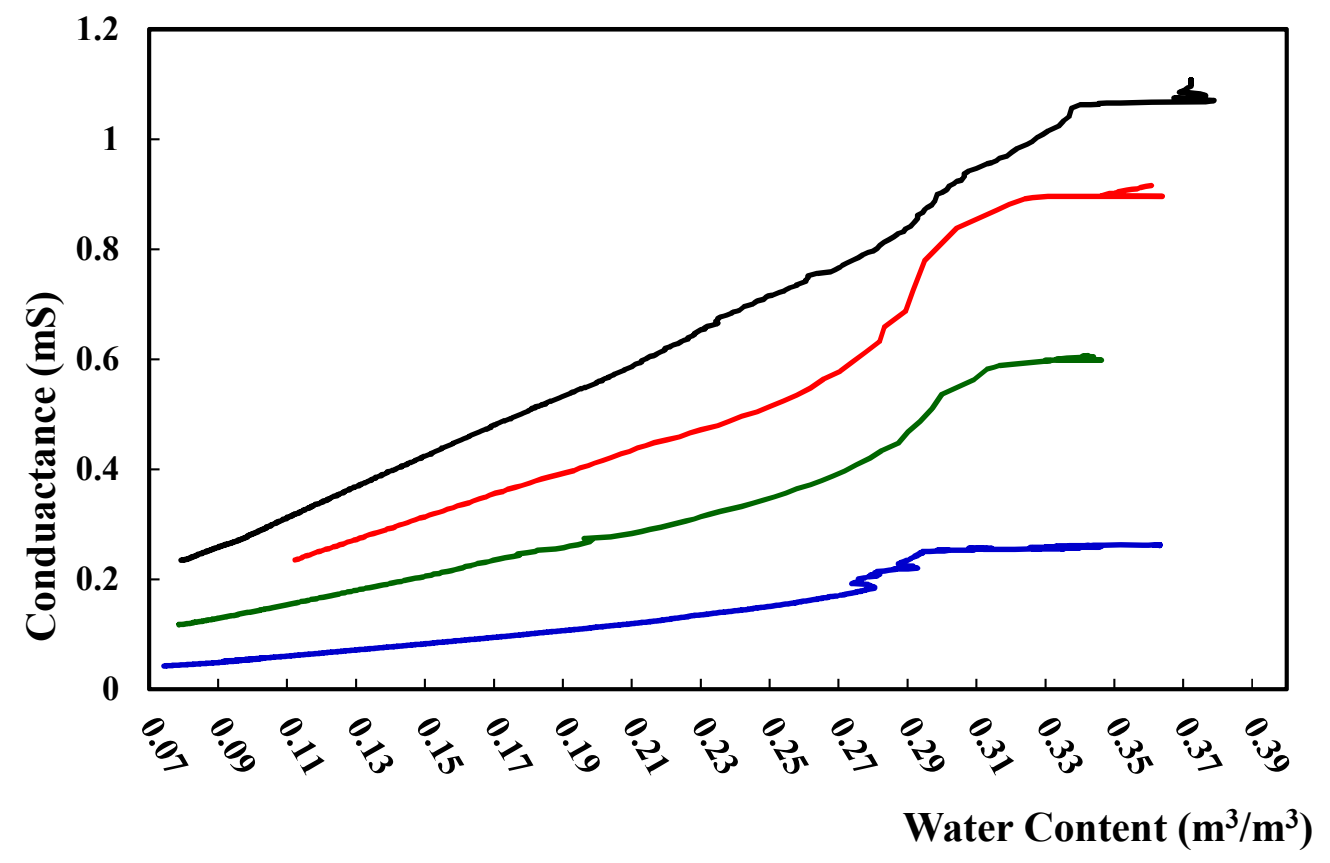

-Cycle 1 -Cycle $2-$ Cycle 3 Cycle 4

Fig. 5. Conductance versus water content plots for Leighton Buzzard sand.

During the course of the experiments it was necessary to alter the conductivity sensor drive current levels in order to maintain the sensor output voltages within the measurable range of the conductivity sensor interface circuit $(<4.5 \mathrm{~V})$. Specifically, at lower conductance levels (in drier sand) the drive current had to be reduced. By the fourth cycle it had to be reduced from an initial level of $1 \mathrm{~mA}$ for the first and second cycles to a final level of $0.1 \mathrm{~mA}$. It was noted that the drainage rates for the soil column decreased from an initial value of $1.06 \mathrm{~mL} / \mathrm{s}$ to 0.24 $\mathrm{mL} / \mathrm{s}$ by the fourth cycle. Values of conductivity sensor drive current used and the drainage rates encountered for each cycle were as follows. Cycle 1: $1 \mathrm{~mA}(1.06 \mathrm{~mL} / \mathrm{s})$, Cycle 2: $1 \mathrm{~mA}$ $(0.67 \mathrm{~mL} / \mathrm{s})$, Cycle 3: $0.5 \mathrm{~mA}(0.97 \mathrm{~mL} / \mathrm{s})$ and Cycle 4: $0.1 \mathrm{~mA}(0.24 \mathrm{~mL} / \mathrm{s})$.

The soil porosity (volume voids/total volume) multiplied by its saturation (volume of water/volume of voids) gives the volumetric water content. Hence the measured column soil dry density of $1.79 \mathrm{Mg} / \mathrm{m}^{3}$ has a theoretical porosity $\mathrm{n}=0.32$ and at $100 \%$ saturation, this equates to a volumetric water content of $0.32 \mathrm{~m}^{3} / \mathrm{m}^{3}$. Interestingly, this corresponds to the point on the curve when the conductance initially starts to drop. The maximum water content recorded in each subsequent cycle also appears to drop, which tends to suggest a change in the packing of the particles e.g. wetting collapse. An alternative explanation could be that there is increasing air trapped, and hence the maximum saturation is reducing with successive cycles. Fig. 6 shows plots of conductance versus water content for the Builders' sand over three cycles of wetting and draining of the soil column. Again, sensor drive current levels had to be reduced from an initial value of $0.25 \mathrm{~mA}$ to a final value of $0.1 \mathrm{~mA}$ to maintain the sensor output voltage readings within the measurable range of the instrumentation. Drainage rates in cycle 1 varied from an initial $0.05 \mathrm{~mL} / \mathrm{s}$ up to $0.25 \mathrm{~mL} / \mathrm{s}$ by the end of the cycle, while both Cycle 2 and Cycle 3 maintained a stable value of around $0.35 \mathrm{~mL} / \mathrm{s}$. 


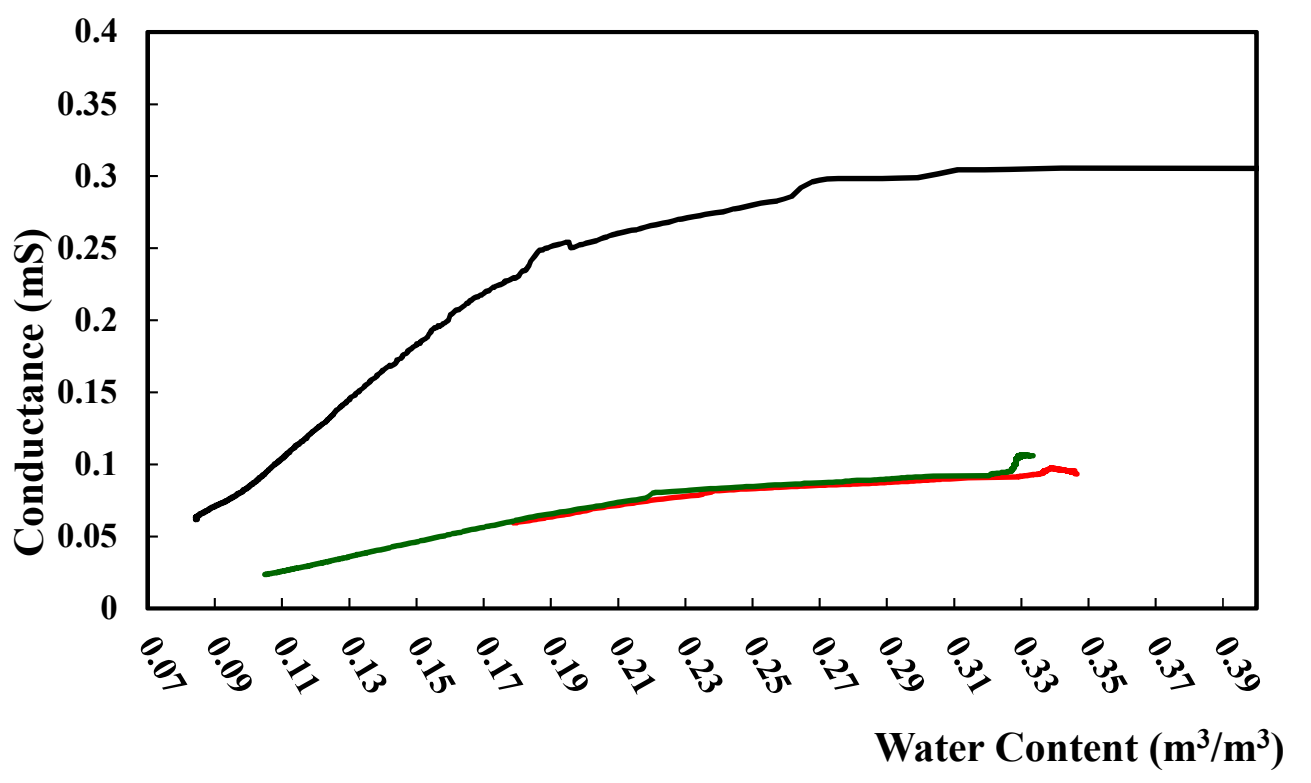

—Cycle 1 -Cycle 2 Cycle 3

Fig. 6. Conductance versus water content plots for Builders' sand.

Fig. 6 shows that for the Builders' sand, both the absolute value of conductance and the slope of conductance versus water content were found to reduce over successive drainage cycles from initially higher values in Cycle 1 to lower and more repeatable values in subsequent cycles. It was also notable that the column drainage rate initially increased during the first cycle and then appeared to stabilise for further cycles.

Fig. 7 shows plots of conductance versus water content for the Sand-Silt-Clay soil mixture over two cycles of wetting and draining of the soil column.

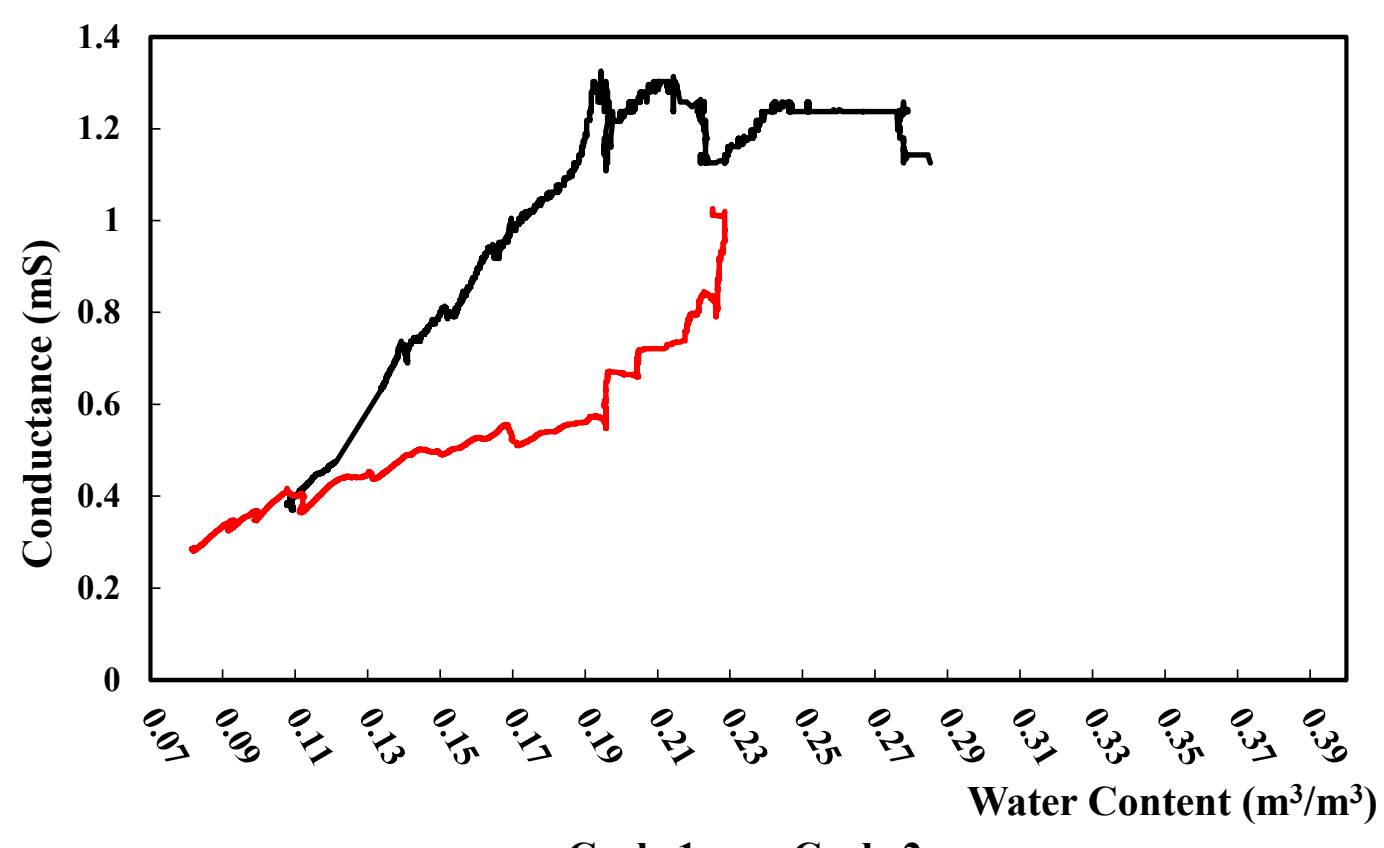

—Cycle 1 Cycle 2

Fig. 7. Conductance versus water content plots for Sand-Silt-Clay mixture.

Again, as with the other soil types, both the absolute value of conductance and the slope of conductance versus water content were seen to reduce over successive drainage cycles from 
initially higher values in the first cycle. The measured dry density for the Sand-Silt-Clay mixture of $2.09 \mathrm{Mg} / \mathrm{m}^{3}$ corresponds to a theoretical value of porosity $\mathrm{n}=0.21$ and hence saturated volumetric water content of $0.21 \mathrm{~m}^{3} / \mathrm{m}^{3}$, which again seems broadly consistent with the point where the conductance initially begins to drop. Also it was noticeable that the curves are not as smooth as for the sands, which could be caused by the low permeability of the material, and its inability to freely drain. Thus air drying of the column may also occur and this could be affected by diurnal variations in the temperature of the material etc.

Fig. 8 compares plots of conductance versus water content for the three different soil mixtures during the first two cycles of wetting and draining of the soil columns.

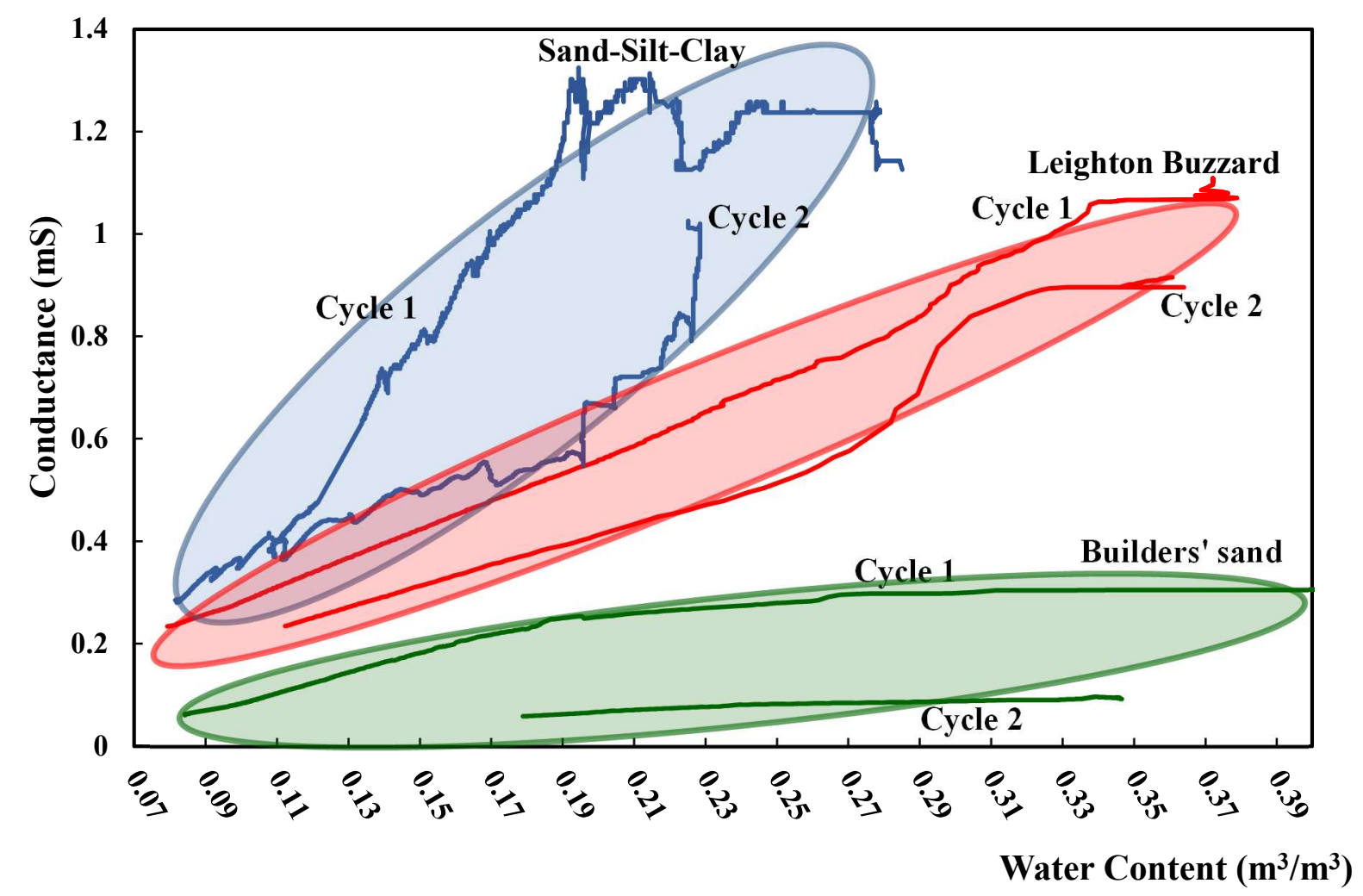

Fig. 8. Conductance versus water content plots for all soil types for the first two cycles.

It can be seen that the three different soil types exhibit quite distinct patterns of conductance change versus water content. Both the absolute values of conductance and the slope of the conductance versus water content plot are lower for the coarser grained Builders' sand and exhibit increasingly higher values for the smaller grained LB sand and the even smaller grained and denser Sand-Silt-Clay soil mixture. Inspection of the slopes of these plots shows that the rate of change of conductivity with water content exhibits distinctly different but consistent patterns for the three different soil types. The slope of the conductance versus water content curve for the finer LB sand is steeper than that of the Builders' sand, and the Sand-Silt-Clay mixture curve is steeper than for both sands. It is also apparent that the rate of change of conductivity versus water content exhibits progressive change with subsequent wetting and drying cycles.

\section{Discussion}

It is particularly noticeable that subsequent wetting and drying cycles of the LB sand resulted in significant decreases in the soil conductivity. This phenomenon has also been reported elsewhere $[8,23]$. Significantly, a concomitant reduction in the slope of the conductivity versus 
water content curves was also observed, indicating that a lower degree of conductance change takes place during subsequent cycles. The assumption is made here that conduction through the sand is primarily via water filled channels between the sand grains and that the sand grains themselves play little or no part in the conduction mechanism. Hence both of these observed phenomena can be ascribed to some form of restructuring of the soil resulting from the cyclic wetting/drying. This restructuring could take the form of deterioration in soil fabric such as a 'wash out' of finer particles of sand from the top of the soil column towards the bottom, resulting in a change in porosity for subsequent wetting/drying cycles. This particle size distribution change may then leave a different distribution of water through the sample, potentially changing the conductance by changing conducting path lengths due to changes in sample tortuosity.

The same phenomena were found to exist with the Builders' sand and the Sand-Silt-Clay mixture in that subsequent wetting and drying cycles produced a decrease in the soil conductivity together with a reduction in the slope of the conductivity versus water content curves.

The fitting of simple, first order characteristics to the plots of conductance versus water content produces slope factors $\left(\frac{\mathrm{ms}}{\left(\mathrm{m}^{3} / \mathrm{m}^{3}\right)}\right)$ for each cycle and soil type. The resultant conductance versus water content (CWC) slope factors can then be considered as soil structure approximators that can be used to allow comparisons between the different soil types and different wetting/drying cycles. Fig. 9 shows plots of the CWC slope factors of conductivity versus water content for all three soil types plotted against the number of wetting/drying cycles.

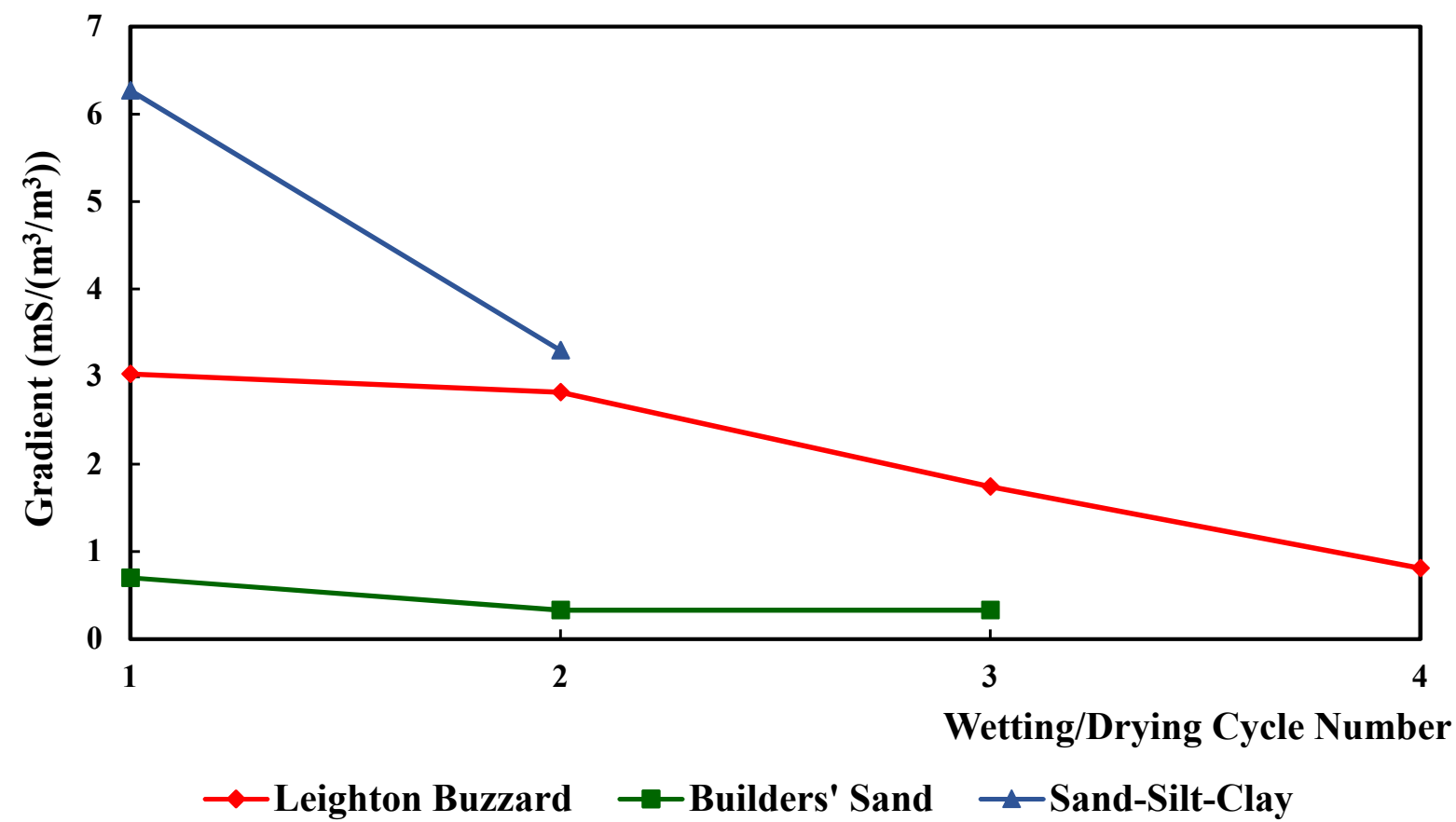

Fig. 9. First order slope factors as CWC plots $\left(\frac{m s}{\left(m^{3} / m^{3}\right)}\right)$ for all three soil types plotted as a function of number of wetting/drying cycles.

Fig. 9 clearly indicates that a reduction in the slope of the CWC characteristic for all three soil types takes place as the number of wetting/drying cycles increases, with the reduction being more pronounced for the finer grained soils.

A simple model for conduction in fluid filled soil has previously been proposed [24] where the soil conductivity $\sigma_{s}$ is given by Eqn. (1): 


$$
\sigma_{s}=\frac{S \cdot n \cdot \sigma_{l}}{\alpha}
$$

where $S$ is the degree of saturation (\%), $n$ is the porosity, $\alpha$ is the tortuosity and $\sigma_{l}$ is the conductivity of the liquid phase $(\mathrm{S} / \mathrm{m})$. Rearranging Eqn. (1) to show the slope of conductivity versus water content yields Eqn. (2):

$$
\frac{\sigma_{s}}{S \cdot n}=\frac{1}{\alpha} \cdot \sigma_{l}
$$

The fact that $\left(\frac{\sigma_{S}}{S \cdot n}\right)$, (where $(S \cdot n)$ is equal to the volumetric water content), was found to decrease with successive wetting and drying cycles, would tend to suggest the tortuosity $\alpha$ was increasing. Another possibility is that the conductivity of the liquid phase $\sigma_{l}$ was decreasing. Since a wash out of finer particles that leaves the remaining soil structure otherwise unchanged is only likely to increase porosity and reduce tortuosity, it has to be concluded that either the liquid phase conductivity is decreasing or the simple soil conductivity model does not apply in this instance. The simple model assumes a relatively homogenous dispersion of water within the soil voids as opposed to a model whereby conduction channels may develop over the surfaces of the grains through a process of wetting.

Another perhaps stronger possibility is that structural collapse of the soil occurs following wash out of finer particles thereby reducing porosity and increasing tortuosity. However, the role of the finer particles in the conduction of the liquid phase must also be considered in that some of them may also have contributed, e.g. as ionic salts, to the conduction mechanism within the water filled channels. It was clear from the visual appearance of sand soils within the columns that the soil structure had changed and a form of structural deterioration, e.g. wetting collapse, had taken place. While the idea of using a Sand-Silt-Clay mixture over a pure clay soil was to help reduce volume change and cracking from the clay constituent, it is possible that drying does cause microcracking which changes the structure of the material, as has been observed elsewhere [8]. Both deterioration mechanisms (wash-out/collapse, and microcracking) have the potential to change the soil water retention behaviour, and the shear strength of the soil. It is proposed that these potential phenomena be investigated as a follow-on study, using video imaging and particle tracking of the soil columns.

It is worth mentioning that these relationships are also dependent on the conductivity/ionic content of the liquid phase. However, using the absolute values recorded from the conductivity sensor, this dependency can be taken into account and removed.

\section{Conclusions}

It is clear that there are significant differences in the relationship between electrical conductivity and water content for the different types of soil tested. It is also clear that cyclic wetting and draining of the soils, such as would occur due to natural climate effects, produces changes in the conductance versus water content characteristics that are suggestive of soil structural change. It is postulated here that an instrument capable of simultaneously tracking both changes in water content and the resulting conductivity changes, would be able to monitor soil structural change by recognising changes in the conductivity versus water content CWC characteristic. This could easily be achieved using the compact and low cost thick film sensors utilised in the work reported here, together with a simple embedded microprocessor to implement the algorithms. This approach would of course depend on there being a cyclic nature to the water content of the soil such as would result from periodic rainfall or seasonal water cycles, but this situation is not untypical in many earthworks such as embankments and cuttings. What is not yet fully understood is whether these detected changes in soil structure can reliably be used to 
infer or predict instability in earthworks, and consequently this will be an area of great interest and ongoing research activity.

\section{Acknowledgement}

The authors wish to thank the UK Natural Environmental Research Council (Grant Number NE/I006877) and the Network Rail Strategic University Partnership in Future Infrastructure Systems for partial funding of this work. The authors would also like to gratefully acknowledge the support of NVIDIA Corporation with the donation of the Quadro P5000 GPU used for this research.

\section{References}

[1] C. Power, J. Mian, T. Spink, S. Abbott, M. Edwards, Development of an Evidence-based Geotechnical Asset Management Policy for Network Rail, Great Britain, Procedia Eng. 143 (2016) 726-733. doi:10.1016/j.proeng.2016.06.112.

[2] A. Mori, S.S. Subramanian, T. Ishikawa, M. Komatsu, A Case Study of a Cut Slope Failure Influenced by Snowmelt and Rainfall, Procedia Eng. 189 (2017) 533-538. doi:10.1016/j.proeng.2017.05.085.

[3] K.M. Briggs, J.A. Smethurst, W. Powrie, A.S. O'Brien, Wet winter pore pressures in railway embankments, Proc. Inst. Civ. Eng. - Geotech. Eng. 166 (2013) 451-465. doi:10.1680/geng.11.00106.

[4] K. Martinović, K. Gavin, C. Reale, Development of a landslide susceptibility assessment for a rail network, Eng. Geol. 215 (2016) 1-9. doi:10.1016/j.enggeo.2016.10.011.

[5] J.E. Chambers, D.A. Gunn, P.B. Wilkinson, P.I. Meldrum, E. Haslam, S. Holyoake, M. Kirkham, O. Kuras, A. Merritt, J. Wragg, 4D electrical resistivity tomography monitoring of soil moisture dynamics in an operational railway embankment, Near Surf. Geophys. 12 (2014) 61-72. doi:10.3997/1873-0604.2013002.

[6] F.A. Loveridge, T.W. Spink, A.S. O’Brien, K.M. Briggs, D. Butcher, The impact of climate and climate change on infrastructure slopes, with particular reference to southern England, Q. J. Eng. Geol. Hydrogeol. 43 (2010) 461-472.

[7] J.A. Smethurst, D. Clarke, W. Powrie, Seasonal changes in pore water pressure in a grass-covered cut slope in London Clay, Geotechnique. 62 (2012) 429-446. doi:10.1680/ssc.41080.0029.

[8] R.M. Hen-Jones, P.N. Hughes, R.A. Stirling, S. Glendinning, J.E. Chambers, D.A. Gunn, Y.J. Cui, Seasonal effects on geophysical-geotechnical relationships and their implications for electrical resistivity tomography monitoring of slopes, Acta Geotech. (2017) 1-15. doi:10.1007/s11440-017-0523-7.

[9] A.J. Merritt, J.E. Chambers, P.B. Wilkinson, L.J. West, W. Murphy, D. Gunn, S. Uhlemann, Measurement and modelling of moisture-electrical resistivity relationship of fine-grained unsaturated soils and electrical anisotropy, J. Appl. Geophys. 124 (2016) 155-165. doi:10.1016/j.jappgeo.2015.11.005.

[10] J. Gance, J.P. Malet, R. Supper, P. Sailhac, D. Ottowitz, B. Jochum, Permanent electrical resistivity measurements for monitoring water circulation in clayey landslides, J. Appl. Geophys. 126 (2016) 98-115. doi:10.1016/j.jappgeo.2016.01.011.

[11] M. Russel, S. Zhenxiang, L. Changrui, Z. Hao, L. Lifen, S. Marios, Z. Yong, Development of a detection method based on dielectric spectroscopy for real-time 
monitoring of meta-cresol contamination in beach-sand, Sensors Actuators, A Phys. 268 (2017) 16-26. doi:10.1016/j.sna.2017.10.049.

[12] M. Sophocleous, J. Georgiou, Precision agriculture: Challenges in sensors and electronics for real-time soil and plant monitoring, 2017 IEEE Biomed. Circuits Syst. Conf. (2017) 1-4. doi:10.1109/BIOCAS.2017.8325180.

[13] H. Awang, I.A.A. Bakar, F. Ismail, A. Alisibramulisi, E. Benjamin, Slope failure investigation using electrical resistivity profiling, J. Teknol. 78 (2016) 9-13. doi:10.11113/jt.v78.8568.

[14] J.A. Smethurst, A. Smith, S. Uhlemann, C. Wooff, J. Chambers, P. Hughes, S. Lenart, H. Saroglou, S.M. Springman, H. Löfroth, D. Hughes, Current and future role of instrumentation and monitoring in the performance of transport infrastructure slopes, Q. J. Eng. Geol. Hydrogeol. 50 (2017) 271-286. doi:10.1144/qjegh2016-080.

[15] S. Szalai, K. Szokoli, M. Metwaly, Z. Gribovszki, E. Prácser, Prediction of the location of future rupture surfaces of a slowly moving loess landslide by electrical resistivity tomography, Geophys. Prospect. 65 (2017) 596-616. doi:10.1111/1365-2478.12421.

[16] M. Sophocleous, P. Savva, M.F. Petrou, J.K. Atkinson, J. Georgiou, A durable, screenprinted sensor for in-situ and real-time monitoring of concrete's electrical resistivity suitable for smart buildings/cities and IoT, IEEE Sensors Lett. (2018).

[17] M. Sophocleous, J.K. Atkinson, A novel thick-film electrical conductivity sensor suitable for liquid and soil conductivity measurements, Sensors Actuators, B Chem. 213 (2015) 417-422. doi:10.1016/j.snb.2015.02.110.

[18] J.K. Atkinson, M. Sophocleous, A novel thick-film screen printed electrical conductivity sensor for measurement of liquid and soil conductivity, IEEE SENSORS 2014 Proc. 2014-Decem (2014) 86-89. doi:10.1109/ICSENS.2014.6984939.

[19] J.K. Atkinson, M. Glanc, M. Prakorbjanya, M. Sophocleous, R. Sion, E. Garcia Breijo, Thick film screen printed environmental and chemical sensor array reference electrodes suitable for subterranean and subaqueous deployments, Microelectron. Int. 30 (2013) 92-98. doi:10.1108/13565361311314485.

[20] M. Sophocleous, Thick-Film Underground Sensors, LAP LAMPERT Academic Publishing, 2016.

[21] Marios Sophocleous (May 31st 2017). Electrical Resistivity Sensing Methods and Implications, Electrical Resistivity and Conductivity, Adel El Shahat, IntechOpen, DOI: 10.5772/67748. Available from: https://www.intechopen.com/books/electricalresistivity-and-conductivity/electrical-resistivity-sensing-methods-and-implications

[22] M. Sophocleous, E. Garcia-Breijo, J.K. Atkinson, J. Georgiou, Modeling \& Performance Comparison of Screen-Printed, Impedance Spectroscopy Probes for Harsh Environments, IEEE Sens. J. (2019). doi:10.1109/JSEN.2019.2951200.

[23] L. Chen, Z. Yin, P. Zhang, Relationship of Resistivity with Water Content and Fissures of Unsaturated Expansive Soils, J. China Univ. Min. Technol. 17 (2007) 537-540.

[24] Y. Mao, E. Romero, A. Gens, Exploring ice content on partially saturated frozen soils using dielectric permittivity and bulk electrical conductivity measurements, in: 3rd Eur. Conf. Unsaturated Soils - "E-UNSAT 2016," 2016: p. 6. doi:10.1051/e3sconf/20160907005. 